\title{
CASO NINTENDO: ¿EVOLUCIÓN O INVOLUCIÓN \\ EN LA PROTECCIÓN DEL DISEÑO COMUNITARIO? COMENTARIO DE LA SENTENCIA DE 27 DE SEPTIEMBRE DE 2017, ASUNTOS ACUMULADOS C-24/16 Y C-25/16
}

\author{
NINTENDO CASE: EVOLUTION OR INVOLUTION \\ IN THE PROTECTION OF COMMUNITY DESIGN? COMMENT \\ ON THE JUDGMENT OF SEPTEMBER 27, 2017, JOINED \\ CASES C-24/16 AND C-25/16
}

\author{
VANESSA JimÉNEZ SERRANÍA \\ Profesora Asociada (Acreditada a Contratado Doctor) \\ Secretaria del Instituto Multidisciplinar de Empresa \\ Universidad de Salamanca \\ ORCID ID:0000-0002-2078-5648
}

Recibido: 15.07.2019 / Aceptado: 02.09.2019

DOI: https://doi.org/10.20318/cdt.2019.4985

\begin{abstract}
Resumen: La STJUE de 27 de septiembre de 2017, más conocida como "asunto Nintendo" supone un importante hito jurisprudencial en la materia del diseño comunitario. El TJUE, en esta sentencia, aborda ciertos aspectos clave derivados de la aplicación práctica, a nivel procesal, de la protección otorgada por el diseño comunitario en casos en los que existen una pluralidad de infractores situados en distintos Estados Miembros que, a su vez, comercializan productos para varios países a través de Internet. En segundo lugar, en esta sentencia se determinan, de una manera cuestionable, los contornos a un límite poco conocido y estudiado de los derechos otorgados al titular de un diseño comunitario: el límite de "cita".

Palabras clave: diseño comunitario, litisconsorcio pasivo, pretensiones accesorias, Internet, ley aplicable, límite de cita
\end{abstract}

\begin{abstract}
The Judgment of the CJEU of September 27th, 2017, better known as the "Nintendo case" represents an important jurisprudential milestone in the field of community design protection. The CJEU, in this Judgment, addresses certain key aspects related to the practical application, at the procedural level, of the protection granted by the Community design. In particular, it examines the case in which there is a plurality of offenders located in different Member States who market products for several countries via Internet. Secondly, in this judgment the CJEU determines, in a questionable manner, the contours to an "almost" unknown restriction of the rights granted to the holder of a community design: the "citation" limitation.
\end{abstract}

Keywords: community design, passive joint litigation, accessory claims, Internet, applicable law, appointment limit.

Sumario: I. Introducción. 1. Consideraciones preliminares. 2. Descripción de los hechos. II. Cuestiones procesales. 1. Litisconsorcio pasivo. 2. Competencia sobre las "pretensiones accesorias" y alcance de la resolución del tribunal en casos de litisconsorcio pasivo. III. Cuestiones sobre la ley 
aplicable a las pretensiones accesorias. IV. Cuestiones materiales: El alcance del límite de "cita" en los diseños comunitarios. 1. Aprehensión del límite de cita en el caso Nintendo. 2. Reflexiones relativas a la interpretación del límite de cita de la sentencia Nintendo. V. Consideraciones finales.

\section{Introducción}

\section{Consideraciones Preliminares}

1. La STJUE de 27 de septiembre de 2017 en los asuntos acumulados C-24/16 y C-25/16 (de aquí en adelante, "asunto Nintendo") supone un importante hito jurisprudencial en la materia del diseño comunitario. Esto se debe a dos razones fundamentalmente. En primer lugar, en esta sentencia, el TJUE aborda ciertos aspectos clave derivados de la aplicación práctica, a nivel judicial, de la protección otorgada por el diseño comunitario en casos en los que existen una pluralidad de infractores situados en distintos Estados Miembros que, a su vez, comercializan productos para varios países a través de Internet. En segundo lugar, en esta sentencia se determinan por primera vez los contornos a un límite poco conocido y estudiado de los derechos otorgados al titular de un diseño comunitario: el límite de "cita".

2. En el presente comentario se pretende ofrecer una visión sucinta y crítica de cada uno de estos aspectos abordados por el TJUE partiendo de una descripción del asunto Nintendo a fin de poner en perspectiva los diferentes elementos estudiados.

\section{Descripción de los hechos}

3. El origen del asunto Nintendo lo encontramos en un litigio que enfrentaba en Alemania a la conocida empresa nipona Nintendo contra la empresa francesa BigBen Interactive SA (de aquí en adelante, "BigBen Francia") y su filial alemana BigBen Interactive GmbH (de aquí en adelante, "BigBen Alemania").

BigBen Francia es una empresa que se dedica a fabricar mandos y otros accesorios compatibles con la consola de videojuegos Wii (producto de la empresa Nintendo). Con anterioridad al inicio de la controversia, BigBen Francia vendía directamente estos accesorios compatibles desde su página web a consumidores de Francia, Bélgica y Luxemburgo. Por otro lado, BigBen Francia vendía estos productos a su filial en Alemania, quien los comercializaba, también, a través de su página web, en Alemania. No obstante, BigBen Alemania no distribuía directamente los productos que comercializaba, ya que no disponía de stock almacenado en Alemania, sino que estos productos eran distribuidos desde Francia bajo pedido realizado por la filial a la matriz. Dicho de otra manera, cada vez que un consumidor hacía un pedido en la página web de BigBen Alemania, ésta solicita el envío del mismo a su matriz (BigBen Francia), quien lo distribuía desde sus almacenes en Francia ${ }^{1}$.

4. Estas conductas descritas podrían parecer inocuas, ya que, per se, la fabricación y comercialización de accesorios compatibles (esto es, interoperables) con la citada consola supone una actividad perfectamente legítima. No obstante, según se manifestó por parte de Nintendo, dichos mandos y accesorios reproducían diseños comunitarios de los que era titular Nintendo. Junto con estas conductas, BigBen Francia y BigBen Alemania reproducían imágenes estos diseños comunitarios en sus páginas web respectivas a efectos publicitarios respecto a estos accesorios comercializados ${ }^{2}$.

5. En vista de estas acciones Nintendo consideró que BigBen Francia y BinBen Alemania infringían sus dibujos comunitarios y tomó la decisión de demandar ante el Landgericht Düsseldorf (Tribunal Regional Civil y Penal de Düsseldorf) tanto a BigBen Alemania como a BigBen Francia.

El Landgericht Düsseldorf se declaró competente tanto para juzgar a la empresa alemana como a la francesa y declaró la existencia de una infracción por parte ambas respecto a los diseños comunita-

\footnotetext{
${ }^{1}$ STJUE 27 de septiembre de 2017, asuntos acumulados C-24/16 y C-25/16, Nintendo, ECLI:EU:C:2017:724, § 23, 24.

2 STJUE Nintendo, $\S 25$.
} 
rios registrados por Nintendo. No obstante, sólo consideró como ilícitas las conductas de explotación de estos diseños en la producción y distribución de productos, desestimando, por tanto, calificar el uso de imágenes de estos diseños a efectos publicitarios como violación del derecho exclusivo.

Por consiguiente, este tribunal condenó ambas empresas a cesar en el uso de los mencionados dibujos y modelos en territorio de la Unión y, además, estimó las pretensiones conexas de Nintendo (transmisión de diversa información, cuentas y documentos en poder de las demandadas en los litigios principales, que se declarara la obligación de indemnizarla, que se ordenara la destrucción y la retirada de los productos controvertidos y la publicación de la sentencia y que se le reembolsaran a Nintendo los honorarios de abogados abonados por ella) ${ }^{3}$.

6. En la decisión tomada por el Landgericht Düsseldorf son reseñables, por controvertidos, dos aspectos:

- en primer lugar, respecto a las pretensiones conexas, el tribunal, pese a que limita el alcance material de su decisión a los comportamientos vinculados a los productos controvertidos comercializados desde BigBen Alemania ${ }^{4}$, no limita el alcance territorial de su resolución;

- en segundo lugar, el tribunal considera como derecho aplicable "el del lugar de la infracción", esto es "el derecho alemán, el austriaco y el francés"s.

7. Esta sentencia es recurrida ante el Oberlandesgericht Düsseldorf (Tribunal Superior Regional Civil y Penal de Düsseldorf), quien plantea las siguientes cuestiones prejudiciales:

“1) En un procedimiento de reclamación de derechos derivados de un dibujo o modelo comunitario, el tribunal de un Estado miembro cuya competencia en relación con un demandado se fundamenta únicamente en el artículo 79, apartado 1, del (Reglamento $\left.n^{\circ} 6 / 2002\right)$, en relación con el artículo 6, punto 1, del (Reglamento $n^{\circ} 44 / 2001$ ), debido a que dicho demandado, que reside en otro Estado miembro, suministró al demandado residente en el Estado miembro del tribunal productos que posiblemente infrinjan los derechos de propiedad intelectual, ¿puede ordenar contra el demandado mencionado en primer lugar diligencias que tengan validez en toda la Unión y que no se limiten a las relaciones de suministro en que se fundamenta la competencia?

2) ¿Debe interpretarse el (Reglamento $\left.n^{\circ} 6 / 2002\right)$, en particular su artículo 20, apartado 1, letra c), en el sentido de que un tercero puede reproducir un dibujo o modelo comunitario con fines comerciales si desea distribuir accesorios para productos del titular conformes con el dibujo o modelo comunitario? Si es así, ¿qué criterios se han de aplicar?

3) ¿Cómo se ha de determinar el lugar "en el que se haya cometido la infracción” a efectos del artículo 8, apartado 2, del (Reglamento ${ }^{\circ}$ 864/2007), en los casos en que el infractor: a) ofrece en un sitio de Internet productos que vulneran un dibujo o modelo comunitario y dicho sitio de Internet está dirigido (también) a otros Estados miembros distintos de aquel en que está establecido el infractor, y b) hace transportar dichos productos a otro Estado miembro distinto de aquel en que está establecido?

¿Debe interpretarse el artículo 15, letras a) y g), del mencionado Reglamento en el sentido de que la ley aplicable así determinada se aplica también a los actos de participación de otras personas?"6

8. En definitiva, se plantean al TJUE cuatro cuestiones clave relativas a la configuración transversal de la regulación jurídica del diseño comunitario, que se imbrican en el orden procesal (la competencia judicial de los tribunales de diseños comunitarios en casos de litisconsorcio pasivo respecto a la emisión de resoluciones sobre pretensiones conexas a la principal y el alcance territorial de estas resoluciones; II); en el internacional privado (la ley aplicable en el caso de diferentes conductas infractoras de un diseño comunitario cometidas en distintos Estados Miembros; III) y en la propiedad industrial (la interpretación del límite de cita en el diseño comunitario; IV).

\footnotetext{
${ }^{3}$ STJUE Nintendo, § 26-27.

${ }^{4}$ Por tanto, en el caso de BigBen Francia quedarían comprendidos exclusivamente los productos que distribuyó por indicación de su filial en Alemania y Austria.

${ }^{5}$ STJUE Nintendo, $\S 28$.

${ }^{6}$ STJUE Nintendo, $\S 36$.
} 


\section{Cuestiones procesales}

9. Cómo decíamos en el apartado anterior una de las cuestiones claves es la competencia judicial de los tribunales de diseños comunitarios. En este asunto, se dirime esencialmente si el caso de litisconsorcio pasivo sería posible sólo para aquellas acciones principales ligadas con el litigio en cuestión o si podría extenderse también a pretensiones accesorias a las mismas?

10. Esta cuestión se centra, por tanto, en la interrelación entre dos sistemas normativos diferentes: por un lado, la normativa propia a los diseños comunitarios (Reglamento $\mathrm{n}^{\circ} 6 / 2002$ del Consejo de 12 de diciembre de 2001, sobre los dibujos y modelos comunitarios, de aquí en adelante, "RDC" $)$ y, por otro, las normas de aplicación general (en el momento de los hechos, el Reglamento (CE) n ${ }^{\circ} 44 / 2001$ del Consejo, de 22 de diciembre de 2000, relativo a la competencia judicial, el reconocimiento y la ejecución de resoluciones judiciales en materia civil y mercantil, de aquí en adelante, "Reglamento Bruselas I").

\section{Litisconsorcio pasivo}

11. Recordemos brevemente, que el RDC establece en su art. 81 que, una serie de acciones sobre las que los tribunales de dibujos y modelos comunitarios ${ }^{9}$ tendrán competencia exclusiva, destacándose, entre ellas, las de infracción del diseño comunitario ${ }^{10}$. Los criterios para la consideración de la competencia internacional de estos tribunales quedan recogidos en el art. $82 \mathrm{RDC}$, donde se intenta abarcar todas las situaciones posibles del espectro. En primer lugar, tendríamos en el apartado 4 del artículo 82 $\mathrm{RDC}$, la atribución competencia a un tribunal de diseños y modelos comunitarios de un Estado miembro en base a los artículos 17 y 18 del "Convenio de ejecución" (así denominado en el RDC el derogado Convenio de Bruselas de $1968^{11}$ ): la elección de las partes respecto a un tribunal competente y la comparecencia del demandado ante el tribunal. En segundo lugar, en defecto de sumisión expresa o tácita, tendríamos el foro del domicilio del demandado, si estuviera en alguno de los Estados miembros o, si no se cumple esta condición, el de su establecimiento en la UE. En caso de que no se dieran ninguna de estas circunstancias, se abriría la posibilidad, de utilizar el foro del domicilio o el lugar de establecimiento del demandante (en las mismas condiciones que en el caso anterior). En el caso de que no se pudiera encontrar ningún vínculo de los anteriores, se abriría la posibilidad de entablar el procedimiento "ante los tribunales del Estado miembro en que tenga su sede la Oficina" ${ }^{2}$. Esta competencia internacional se refuerza en el apartado 1 del artículo $83 \mathrm{RDC}$, donde se establece que, en los casos mencionados

${ }^{7}$ Estas pretensiones eran las siguientes: "transmisión de diversa información, cuentas y documentos en poder de las demandadas en los litigios principales, que se declarara la obligación de indemnizarla, que se ordenara la destrucción y la retirada de los productos controvertidos y la publicación de la sentencia y que se le reembolsaran a Nintendo los honorarios de abogados abonados por ella". STJUE Nintendo, \$27.

${ }^{8}$ DOCE $n^{\circ}$ L 3 de 5.1.2002, p. 1. modificado por el reglamento (CE) n ${ }^{\circ}$ 1891/2006 del Consejo, de 18 de diciembre de 2006, por el que se modifican los Reglamentos (CE) no 6/2002 y (CE) no 40/94 para hacer efectiva la adhesión de la Comunidad Europea al Acta de Ginebra del Arreglo de La Haya relativo al Registro internacional de dibujos y modelos industriales (DO CE $n^{\circ}$ L 386 de 29.12.2006, p. 14).

${ }^{9}$ Art. 80.1 RDC: “Los Estados miembros designarán en sus territorios respectivos un número tan limitado como sea posible de tribunales nacionales y de primera y segunda instancia ("tribunales de dibujos y modelos comunitarios"), que desempeñarán las funciones que les atribuya el presente Reglamento".

${ }^{10}$ No obstante, el apartado a) del artículo 81 establece como requisito para que puedan conocer de estas acciones que las mismas están "contempladas en la legislación nacional". Estos tribunales de diseños comunitarios también tendrán competencia exclusiva según art.81: "b) sobre las acciones de declaración de inexistencia de infracción con relación a dibujos y modelos comunitarios, si están contempladas en la legislación nacional; c) sobre las acciones de declaración de nulidad de un dibujo o modelo comunitario no registrado; d) sobre las demandas de reconvención para la declaración de nulidad de un dibujo o modelo comunitario interpuestas a raíz de las demandas contempladas en la letra a)".

${ }^{11}$ Convenio de competencia judicial y ejecución de sentencias en materia civil y mercantil, firmado en Bruselas el 27 de septiembre de 1968. DO L 299 de 31.12.1972, p. 32. C. Estas provisiones aparecen recogidas en los artículos 23 y 24 de Reglamento (CE) n ${ }^{\circ}$ 44/2001, y los arts. 25 y 26 del Reglamento (UE) n n 1212/2012 del Parlamento Europeo y del Consejo de 12 de diciembre de 2012 relativo a la competencia judicial, el reconocimiento y la ejecución de resoluciones judiciales en materia civil y mercantil (Bruselas I bis).

${ }^{12}$ Esto es, los tribunales de dibujos y modelos españoles por estar en España la sede de la EUIPO. 
anteriormente, el tribunal será además "competente en materia de violaciones cometidas o que puedan cometerse en el territorio de cualquier Estado miembro".

Por último, respecto a la competencia internacional se menciona en el apartado 5 del artículo 82 la competencia, en los casos de acciones por infracción o intento de infracción y de las demandas reconvencionales, de los tribunales del Estado miembro en el que se hubiera cometido la infracción. No obstante, cómo ha sido subrayado por García Vidal ${ }^{13}$, la competencia internacional de estos tribunales queda limitada en sus efectos, ya que sólo podrán conocer "sobre las violaciones cometidas o que puedan cometerse en el territorio del Estado miembro en el que se encuentre dicho Tribunal"14.

12. El "Convenio de ejecución" señalado con anterioridad, se entiende aplicable a los diseños comunitarios ya que así lo prevé el RDC en su artículo 79, dentro de los límites que tal artículo establece. Por ende, su sucesor el Reglamento Bruselas I, aplicable en el momento de los hechos también lo será.

Respecto a la necesidad de la aplicación de esta norma, hemos de señalar que, en el presente asunto, nos encontramos no sólo con una infracción pluriestatatal y transfronteriza, sino que además, existe una pluralidad de infractores domiciliados en distintos Estados miembros. El RDC plantea la competencia de los tribunales previendo una pluralidad de lugares de comisión de la infracción, pero en ningún momento aporta una solución expresa sobre las competencias en el caso de existencia de varios infractores localizados en distintos Estados miembros implicados en la misma infracción. Es por esto por lo que es necesario recurrir a la norma general donde se establece un foro de vinculación procesal respecto al litisconsorcio pasivo.

Ya el Convenio de Bruselas establecía en su artículo 6.1 que "si hubiera varios demandados (estos podrían ser demandados) ante el juez del domicilio de cualquiera de ellos". Su sucesor, el Reglamento Bruselas I afina este precepto estableciendo en su artículo 6.1 que "si hubiere varios demandados, (podrían ser demandados) ante el tribunal del domicilio de cualquiera de ellos, siempre que las demandas estuvieren vinculadas entre sí por una relación tan estrecha que sería oportuno tramitarlas y juzgarlas al mismo tiempo a fin de evitar resoluciones que podrian ser inconciliables si los asuntos fueren juzgados separadamente" 15 . El "quid" de la cuestión radica, por tanto, en establecer la fuerza vinculatoria entre las distintas demandas ${ }^{16}$.

13. Cómo señalan Calvo Caravaca y Carrascosa González, para poder hacer uso de este litisconsorcio pasivo, serían necesarios, entre otros, los siguientes requisitos: todos los demandados deben estar domiciliados en Estados miembros; los demandados deben presentar alguna vinculación jurídica previa entre sí y las demandas deben estar estrechamente vinculadas debiendo existir esta vinculación estrecha en el momento de tramitación de las mismas. Además, como recuerda la propia sentencia, es necesario que haya riesgo de una divergencia en las soluciones si las demandas se tratan por separado,

${ }^{13}$ A. García Vidal, "Capítulo 7. El contenido del derecho sobre el diseño comunitario" en A. García Vidal (dir)., El diseño comunitario. Estudios sobre el Reglamento (CE) núm. 6/2002, Thomson Reuters Aranzadi, Cizur Menor (Navarra), 2012, p. 443. En el mismo sentido ver, A. BlanCo JiMÉNEZ, "Competencia de los tribunales de dibujos y modelos comunitarios", en A. Blanco Jiménez/ A. Casado Cerviño (aut.), El Diseño Comunitario: Una Aproximación al Régimen Legal de los Dibujos y Modelos en Europa, Thomson Reuters Aranzadi, Cizur Menor (Navarra), 2003, pp.174-179; E. Martínez García, "La organización jurisdiccional en materia de dibujos y modelos industriales" en G. Palao Moreno, M. E. Clemente (coord..), El diseño comunitario, Tirant lo Blanch, Valencia, 2003, pp.275-292.

${ }^{14}$ Este principio es similar al que se aplica en el caso de los litigios sobre marcas de la UE. Cómo señala CARRASCOSA se trata del "Mosaic Principle" o "Mosaikbetrachting", vid. J. Carrascosa González, "Propiedad intelectual e industrial" en A-L. Calvo Caravaca/ J. Carrascosa González (dir.) Derecho Internacional Privado, Vol. II, 17ª ed., Comares, Granada, 2017, p. 1389.

${ }^{15}$ El mismo texto se repite en el art.8.1 del actual Reglamento Bruselas I-bis.

${ }^{16}$ Cómo señalan Calvo Caravaca y Carrascosa González, comentando el art.8.1 bis, este concepto de "vinculación entre las demandas", copia una solución dada por la STJCE 27 septiembre 1988, en el asunto Kalfelis. (Vid. A-L. CALVo CARAVACA y J. CARrascosa GonzÁlez, Litigación internacional en la Unión Europea I: competencia judicial y validez de resoluciones en materia civil y mercantil en la Unión Europea: comentario al Reglamento Bruselas I bis. 1, Thomson Reuters Aranzadi, Cizur Menor (Navarra), 2017). Recordemos que en la parte dispositiva de la STJCE en el asunto Kalfelis se afirmaba que: "Para aplicar el apartado 1 del artículo 6 del Convenio, entre las distintas demandas formuladas por un mismo demandante contra distintos demandados debe existir un punto de conexión, de tal naturaleza, que exista un interés en que sean resueltas conjuntamente, con el fin de evitar soluciones que pudieran ser contradictorias si los litigios se juzgaran por separado". STJ de 27 de septiembre de 1988, asunto 189/87, Kalfelis, ECLI:EU:C:1988:459, § 1. 
siendo preciso que "tal divergencia se inscriba en el marco de una misma situación de hecho y de Derecho" $"$.

14. En el caso en cuestión, tenemos que los requisitos anteriormente mencionados se cumplen ya que ambos demandados se encuentran en Estados miembros (Alemania y Francia), se trata de una sociedad matriz y su filial y las demandas están estrechamente vinculadas ya que existe una misma situación de hecho y de Derecho existente en el momento de tramitación. En cuanto al requisito relativo a la existencia de una misma situación de hecho, el Tribunal remitente entiende (y el TJUE no le contradice) que es suficiente con "la existencia de las entregas de productos supuestamente infractores llevadas a cabo en un primer momento por BigBen Francia a BigBen Alemania y, en un segundo momento, por ésta a sus clientes". ${ }^{18}$ Respecto a la situación de Derecho, se entiende acreditada debido a que cómo formula el tribunal remitente: "debido, en particular, al carácter unitario de los derechos conferidos por un dibujo o modelo comunitario". ${ }^{19}$

\section{Competencia sobre las "pretensiones accesorias" y alcance de la resolución del tribunal en casos de litisconsorcio pasivo}

15. Tanto el Abogado General (de aquí en adelante, "AG") como el TJUE se sirven de los argumentos anteriormente citados para hacer extensiva la competencia del tribunal en este concreto caso de litisconsorcio a las pretensiones accesorias. Esto es, al estar en una misma situación de hecho y de Derecho, no tendría sentido atomizar las decisiones sobre las pretensiones accesorias (especialmente si se trata de medidas coercitivas) atribuyendo la competencia a los tribunales nacionales, ya que se correría el riesgo de que la resolución del tribunal sobre la cuestión principal careciera de efecto disuasorio ${ }^{20}$.

En este caso, además para el TJUE la situación es clara porque estamos ante un derecho de vocación "unitaria", esto es, un derecho que produce los mismos efectos en el conjunto de la Unión, por lo que "la circunstancia de que algunos interdictos que pueda adoptar el tribunal competente para garantizar el respeto de este este derecho dependan de lo dispuesto en el Derecho nacional carece de pertinencia en lo que atañe a la existencia de una misma situación de Derecho a efectos de la aplicación del artículo 6, punto 1, del Reglamento $n^{\circ} 44 / 2001 " 21$.

16. Respecto al alcance territorial de estas decisiones, siguiendo también con el mismo razonamiento y aplicando por analogía la interpretación realizada en la jurisprudencia europea sobre las

${ }^{17}$ STJUE Nintendo, $§ 45$.

${ }^{18}$ STJUE Nintendo, $\S 50$.

19 STJUE Nintendo, $\$ 48$

${ }^{20}$ En este sentido el AG en sus conclusiones (§ 32) hace referencia a sentencias Nokia (STJCE de 14 de diciembre de 2006, asunto C-316/05, EU:C:2006:789, § 60), y DHL Express France (STJUE de 12 de abril de 2011, C-235/09, EU:C:2011:238, § 57) recordando que "la prohibición de continuar los actos de violación y las obligaciones accesorias que derivan de ella, deben considerarse en su totalidad, de tal manera que, sin la existencia de medidas coercitivas, que han de adoptar los tribunales para garantizar el cumplimiento de la resolución de prohibición de la infracción adoptada por el tribunal que conoce del asunto, dicha prohibición carecería de efecto disuasorio". (Conclusiones del Abogado General Sr. Yves Bott (†), presentadas el 1 de marzo de 2017, ECLI:EU:C:2017:146). En consecuencia, no estaría justificado tratar de forma diferente las pretensiones principales y las pretensiones accesorias.

21 STJUE Nintendo, $\S 49$. Recordemos que, respecto a esta cuestión, los demandados habían pretendido la aplicación de la interpretación dada en la Roche Nederland y otros (STJCE de 13 de julio de 2006, asunto C-539/03, Roche Nederland y otros, ECLI:EU:C:2006:458). Recordemos que, en ese asunto, los titulares americanos de una patente europea presentaron una demanda de medidas provisionales ante el Rechtbak te s'-Gravenhage Roche Nederland BV, sociedad establecida en los Países Bajos, así como otras ocho sociedades del grupo Roche, establecidas respectivamente en Estados Unidos de América, Bélgica, Alemania, Francia, Reino Unido, Suiza, Austria y Suecia. Los demandantes reprochaban a las referidas sociedades haber vulnerado los derechos que les confería la patente de la que eran titulares. Esta supuesta vulneración consistía en la comercialización de kits de dosificación inmunológica en los países en los que están establecidas las sociedades demandada (§ 14). Las sociedades del grupo Roche no domiciliadas en los Países Bajo rechazaron la competencia de los tribunales neerlandeses. (§ 15) En este asunto se consideró que no existía ni una misma situación de hecho (ya que los demandados eran diferentes y los actos de violación no eran los mismos, § 27), ni de Derecho (ya que la violación de una patente europea "ha de examinarse a la luz de la normativa nacional en vigor, en la materia, en cada uno de los Estados para los que se ha concedido”, §30-31). 
marcas de la UE, el TJUE afirma que estaríamos ante una situación en la que este alcance viene determinado no sólo por la competencia territorial del tribunal, sino también por el ámbito territorial del derecho exclusivo 22 .

17. Respecto a esta cuestión es remarcable la diferencia en la aproximación realizada por el AG y el TJUE. En sus conclusiones el AG se contenta con dar una explicación deductiva derivada de una aplicación amplia de la extensión de los efectos del derecho exclusivo protegido por el diseño: (no.) "Por otra parte, la protección uniforme, en todo el territorio de la Unión, de los dibujos o modelos comunitarios contra los actos de infracción se vería socavada si las medidas especificas adoptadas a fin de dar cumplimiento a dicha protección carecieran de efecto en todo este territorio y se circunscribieran al territorio en el que radica el órgano jurisdiccional que las adoptó. Los titulares de los dibujos o modelos comunitarios se verían obligados a entablar acciones judiciales ante el tribunal competente de cada Estado miembro, lo que no sólo generaría el riesgo de que se dictasen resoluciones dispares, sino que también supondría un coste significativo para el justiciable". ${ }^{23}$

18. Por su parte, el TJUE intenta, primero, una aproximación hermenéutica del texto del RDC, para posteriormente, determinar su aplicación en una situación de litisconsorcio pasivo derivada del art.6.1 de Reglamento Bruselas I.

En primer lugar, recordemos que mencionábamos que el art.83 del RDC establece el alcance de la competencia de los tribunales de diseño comunitarios. Este alcance vendrá determinado en función del foro por el que el tribunal se declare competente. De esta manera si un tribunal fundamenta su competencia en el foro del domicilio del demandado, ex. art.82.1 RDC (como sería en este caso, el tribunal alemán respecto a BigBen Alemania), sería competente, ex. art.83.1., "en materia de violaciones cometidas o que pudieran cometerse en el territorio de cualquier Estado miembro". Por otro lado, si fundamentamos la competencia del tribunal en el caso de una acción por infracción en el lugar de la comisión de la infracción, ex. art. 82.5, este tribunal sólo será competente, ex. art. 83.2, "sobre las violaciones cometidas o que puedan cometerse en el territorio del Estado miembro en el que se encuentre dicho Tribunal'. En principio, podría parecer, pues, que esta sería, en principio la situación respecto a BigBen Francia.

No obstante, cómo vemos en ninguno de estos casos (ni en ninguna otra parte del RDC) se contempla la situación del litisconsorcio pasivo. Es más, en propio art.82.1 se afirma que serán aplicables, ex. art.79 RDC, las disposiciones del Reglamento Bruselas I. Cómo afirma el TJUE, "no se desprende ni del tenor del artículo 6, punto 1, del Reglamento $n^{\circ} 44 / 2001$ ni de la jurisprudencia del Tribunal de Justicia relativa a éste que los tribunales que conocen legalmente del asunto en virtud de dicho artículo 6 , punto 1, tengan a continuación limitada su competencia territorial respecto del demandado que no está domiciliado en el Estado miembro del foro" "24. Con lo cual, no sería de aplicación en el caso de BigBen France la limitación del alcance territorial establecida en el art.83.2 RDC, sino que, debido a la interpretación conjunta del 82.1 RDC y del art.6.1 del Reglamento de Bruselas, el alcance de la competencia del tribunal sería la establecida en el art.83.1 RDC (i.e., toda la UE). Dicho de otra manera, en el supuesto de un litisconsorcio pasivo en un caso de infracción de diseño industrial, el tribunal del domicilio de uno de los demandados tiene competencia para dictar las sanciones y medidas con un alcance sobre todo el territorio de la UE sobre otro/s infractor/es domiciliado en otros Estados miembros.

\section{Cuestiones sobre la ley aplicable a las pretensiones accesorias}

19. En el presente asunto, cómo ya ha sido mencionado anteriormente, el Landgericht Düsseldorf consideró como derecho aplicable a estas pretensiones "el del lugar de la infracción" (por tanto, al haberse cometido varias infracciones serían aplicables respectivamente el derecho alemán, el austriaco y el francés). Se cuestiona, por tanto, al TJUE, la interpretación del criterio Lex Loci Delictii Commisii

\footnotetext{
${ }^{22}$ STJUE Nintendo, § 53.

${ }^{23}$ STJUE Nintendo, $\$ 34$.

${ }^{24}$ STJUE Nintendo, $§ 63$.
} 
establecido en el art.8.2 del Reglamento (CE) n ${ }^{\circ}$ 864/2007 del Parlamento Europeo y del Consejo, de 11 de julio de 2007, relativo a la ley aplicable a las obligaciones extracontractuales (de aquí en adelante, "Reglamento Roma II").

20. Recordemos que en este precepto se establece que "(e)n caso de una obligación extracontractual que se derive de una infracción de un derecho de propiedad intelectual comunitario de carácter unitario, la ley aplicable será la ley del país en el que se haya cometido la infracción para toda cuestión que no esté regulada por el respectivo instrumento comunitario". Como afirman Calvo Caravaca y Carrascosa González, esta previsión se establece para obligaciones extracontractuales derivadas de la vulneración de estos derechos calificados como "unitarios" y que no estén resultas por los instrumentos legales de la UE. En estos casos, se regirán por la ley del país en el que se haya cometido la infracción de este derecho inmaterial (lex loci delictii commisii) ${ }^{25}$.

21. Antes de empezar a analizar la respuesta a esta cuestión prejudicial, es necesario hacer una puntualización respecto la regulación por el RDC sobre la ley aplicable a los diseños industriales. En el RDC se establece en primer lugar ex art.88 como ley aplicable el RDC (1) y siendo de aplicación, para todas las cuestiones no previstas en el RDC, la legislación nacional del Tribunal de diseños comunitarios que conozca del asunto, incluidas las normas de Derecho internacional privado -lex fori- (2). Por otro lado, encontramos que el tribunal de dibujos y modelos comunitarios puede dictar resoluciones conteniendo "cualquier orden que imponga otras sanciones apropiadas en las circunstancias previstas por la legislación vigente en el Estado miembro en el que se hayan cometido los actos de infracción o de amenaza de infracción, incluidas las normas de Derecho internacional privado" - lex loci delictii commisii (art.89.1 d/).

22. Es remarcable en este punto la diferente aproximación realizada por el $\mathrm{AG}^{26}$ y el TJUE. El AG propone reformular la cuestión planteada por el órgano jurisdiccional remitente centrándose en la interpretación del art. 89.1 d) en lugar de interpretar directamente el art 8.2 del Reglamento Roma II. Esto supondría, primero, determinar si en la expresión "otras sanciones" tendrían cabida las pretensiones accesorias que se pretenden en el caso Nintendo y, en segundo lugar, sería necesario analizar, para la determinación de la ley aplicable, que criterios que han de tomarse en consideración a fin de determinar el lugar en el que se ha cometido el acto de infracción o de amenaza de infracción ${ }^{27}$. El AG determina que ciertas de estas pretensiones estarían incluidas en el art.88.2 RDC y otras en el art.89.1 d).

Respecto a la ley aplicable, el AG comienza estableciendo que el art.8.2 del Reglamento Roma II no será de aplicación en aquellos casos en los que la cuestión se rija por un instrumento comunitario específico ${ }^{28}$. Según el AG en el asunto Nintendo, para una parte de las pretensiones sería de aplicación el art.89.1 d) que establece expresamente la aplicación de la legislación vigente en el Estado miembro en el que se hayan cometido los actos de infracción o de amenaza de infracción (lex loci delictii commisii). Por otro lado, en el caso de las pretensiones que podrían ser incluidas en el art.88.2 RDC, estaríamos a los que establece la legislación nacional, incluidas las normas de derecho internacional privado. En este caso, sería aplicable, pues el art.8.2 del Reglamento Roma II, por lo tanto, la ley aplicable sería también la lex loci delictii commisii.

Pero el AG no se queda aquí si no que va a determinar que concreta ley sería aplicable en el caso en cuestión basándose en la interpretación realizada por el TJUE en el caso Coty Germany, en una cuestión derivada de la infracción de una marca de la UE. En esta sentencia el TJUE va a determinar que el concepto de "territorio [del Estado miembro en que] se hubiere cometido el hecho de [la] violación"

${ }^{25}$ A-L. Calvo Caravaca y J. Carrascosa González, ob.cit, p.1514.

${ }^{26}$ De hecho, la opinión del AG sobre este punto ha sido criticada por considerar su análisis del conflicto de leyes defectuoso (Vid. M. ŚWIERCZYŃSKi/ B. OręziaK, "Judgment of the Court (Second Chamber) of 27 Septembre 2017 in joined cases C-24/16 and 25/16 in the proceedings Nintendo Co.LTD v. BingBen Interactiva GMHB, BigBenInteractive S.A.", Comparative Law Review, n²4, Nicolais Copernicous University, 2018, pp.331-342).

${ }^{27}$ STJUE Nintendo, $\S 40$.

${ }^{28}$ STJUE Nintendo, $\S 53$. 
sugiere [...] que este vínculo de conexión se relaciona con un comportamiento activo del autor de dicha violación. Por tanto, el vínculo de conexión establecido por esta disposición se refiere al territorio del Estado miembro en el que se ha producido el hecho que originó o amenazó con originar la violación alegada, y no al territorio del Estado miembro en el que la mencionada violación produce efectos".

En el caso Nintendo, para el AG, el hecho que originó la supuesta infracción es la fabricación de los productos falsificados ${ }^{29}$, por lo tanto, la ley aplicable sería la francesa.

23. Esta afirmación tan categórica no va a ser compartida por el TJUE en su sentencia, quien además realiza una aproximación diferente respecto a la cuestión del conflicto de leyes. En este caso, si bien el TJUE también determina que ciertas de las "pretensiones accesorias" encontrarían su amparo en el $89.1 \mathrm{~d}$ ) RDC y otras en el 88.2 RDC, se establece que estas reglas no regulan estas sanciones y medidas de manera autónoma ${ }^{30}$, con lo cual habremos de estar en ambos casos a lo establecido en el art.8.2 del Reglamento Roma I.

El quid del problema en este caso va a ser la determinación de ese "país de comisión de la infracción". En este sentido, aunque no la referencia, el TJUE viene adoptar como base la misma solución que se adoptó en el caso Coty Germany de 2014: el concepto de país de comisión de la infracción "se refiere al país en el que se encuentra el lugar en el que se ha producido el hecho generador del daño" ${ }^{31}$. No obstante, el TJUE va más allá ya que afirma que "(e)n circunstancias en las que se reprochan a un mismo demandado distintos actos de infracción cometidos en diferentes Estados miembros, para identificar el hecho generador del daño no es preciso referirse a cada acto de infracción reprochado, sino apreciar de manera global el comportamiento de dicho demandado, a efectos de determinar el lugar en el que éste cometió o pudo cometer el acto de infracción inicial, que está en el origen del comportamiento reprochado" 32 .

Como vemos esta solución matiza y tamiza el criterio enunciado por el AG en sus conclusiones. Además, el TJUE determina, de manera correcta a nuestro juicio, que la infracción de un diseño no sólo viene su utilización no autorizada para la fabricación de productos, sino que puede tratarse de otras conductas como son las oferta, la introducción en el tráfico económico o la importación y exportación ${ }^{33}$. Así el TJUE respondiendo a ciertos de los casos concretos planteados manifiesta lo siguiente:

- Respecto al ofrecimiento a la venta en un sitio internet, se podría considerar como ley aplicable la del lugar "en el que se ha en que se ha iniciado el proceso de publicación de la oferta a la venta por parte de dicho operador en el sitio de su propiedad"34.

- Respecto al transporte a un Estado miembro distinto de aquel en el que está establecido el operador de productos que supuestamente infringen derechos protegidos, se plantea que se ha de "apreciar de manera global el comportamiento de dicho demandado, a efectos de determinar el lugar en el que éste cometió o pudo cometer el acto de infracción inicial, que está en el origen del comportamiento reprochado"35. En este caso, por ejemplo, si podría tratarse de la ley del lugar de fabricación si esta es la infracción inicial.

\section{Cuestiones materiales: El alcance del límite de "cita" en los diseños comunitarios.}

24. En esta sentencia se aborda por primera vez la determinación del contenido y los límites de un precepto poco utilizado y muy poco estudiado por la doctrina: el límite de cita de los diseños industriales. Este límite aparece reflejado en el apartado c) del art.20 RDC en los siguientes términos: "los actos de

\footnotetext{
${ }^{29}$ STJUE Nintendo, $§ 67$.

${ }^{30}$ STJUE Nintendo, $\S 93$.

${ }^{31}$ STJUE de 5 de junio de 2014, asunto C-360/12, Coty Germany, ECLI:EU:C:2014:1318, § 31.

${ }^{32}$ STJUE Nintendo, $\S 111$.

${ }^{33}$ STJUE Nintendo, $\S 101$.

${ }^{34}$ STJUE Nintendo, $§ 108$.

${ }^{35}$ STJUE Nintendo, $§ 109$.
} 
reproducción realizados con fines de cita o docentes, siempre que dichos actos sean compatibles con los usos comerciales, no menoscaben la explotación normal del dibujo o modelo y se mencione la fuente".

Recordemos que en este caso estamos ante una situación en la que una empresa ha utilizado las imágenes de los productos protegidos por el diseño comunitario para realizar la publicidad de sus propios productos.

\section{Aprehensión del límite de cita en el caso Nintendo.}

25. Al analizar esta cuestión, el TJUE intentar un análisis sistemático de la figura en base a sus elementos integradores. En primer lugar, la cuestión que se debe plantear es si esta reproducción realizada por las demandadas es una reproducción en el sentido del artículo 20.1c), puesto que estamos hablando de una reproducción bidimensional de un diseño ${ }^{36}$ que tendrá una representación tridimensional en el espacio. El TJUE considera que esta reproducción bidimensional constituiría en uno de estos actos $(\S 69)^{37}$.

26. Una vez establecida esta premisa, el TJUE pasa a analizar si estamos ante una de las reproducciones comprendidas en el límite de cita. La interpretación dada por el TJUE es claramente procompetidor, ya que interpreta el límite de una manera extensiva ${ }^{38}$. El punto clave de esta cuestión es la consideración que las actividades de reproducción del art.20.1c) han de realizarse en el marco de una actividad comercial (\$75). Dentro de estas actividades estarían comprendidas las situaciones que las que una empresa productora de productos compatibles con productos existentes protegidos por un diseño comunitario titularidad de otra empresa reproduce estos últimos (con fines explicativos o demostrativos) al comercializar de manera lícita sus propios productos ${ }^{39}$.

En todo caso, siempre sería necesario el respecto de los tres requisitos establecidos en el propio artículo $20.1 \mathrm{c})$ :

- Compatibilidad de los actos de reproducción con los usos comerciales;

- Inexistencia de perjuicio indebido (sic) para la explotación normal del dibujo debido a tales actos;

- Mención de la fuente.

Respecto al primero de los requisitos el TJUE determina que estaríamos hablando de los usos leales en materia industrial. Respecto al segundo requisito tendríamos que analizar si esta cita "afect(a) negativamente a los intereses económicos que el titular de los derechos conferidos por los dibujos o modelos comunitarios podría obtener de una explotación normal de dichos dibujos o modelos" (\$82). Respecto al tercer requisito, el TJUE indica que, al no establecerse un modo preciso en el RDC, sería "necesario que el tipo de mención elegida a tal fin permita a un consumidor normalmente informado y razonablemente atento y perspicaz identificar fácilmente el origen comercial del producto que corresponde al dibujo o modelo comunitario" ${ }^{40}$.

27. Si bien el TJUE remite al Oberlandesgericht Düsseldorf la valoración final sobre este asunto, en su sentencia esboza dos pinceladas interesantes sobre el sentido probable de la decisión final. En primer lugar, respecto al segundo de los requisitos, manifiesta que el tribunal remitente ya ha indicado

${ }^{36}$ Tengamos en cuenta que en la publicidad se utilizarán fotografías o representaciones similares de los productos protegidos bajo diseño comunitario.

${ }^{37}$ STJUE Nintendo, $\S 69$. En este sentido el STJUE se hace eco de la opinión vertida por el AG respecto a esta cuestión. El AG adopta el criterio manifestado por Dominique Kaesmacher y Théodora Stamos sobre una interpretación lo más amplia posible del concepto de reproducción (§73).

${ }^{38}$ También respecto a este supuesto el AG manifiesta que es necesaria una interpretación del concepto de "cita" amplia justificándolo los mismos argumentos que utiliza el tribunal: fomento de la innovación. No obstante, como veremos más adelante, en este caso el AG en su reflexión parece incluir en el derecho de cita otro tipo de conductas, como la creación de productos compatibles (§75) aunque matiza esta afirmación con posterioridad $(\S 77)$

${ }^{39}$ STJUE Nintendo, $§ 76$.

${ }^{40}$ STJUE Nintendo, $\S 84$. 
que en este caso se cumple el segundo requisito ${ }^{41}$. En segundo lugar, se indica que, en este caso, los demandados había referenciado dichos diseños mediante la colocación de la marca de la Unión europea titularidad de Nintendo, debiendo el tribunal remitente determinar si la mención es conforme con la materia de marcas $\mathrm{y}$, por ende, (aunque el TJUE no menciona expresamente esta cuestión) con la mención "suficiente" de la fuente del diseño ${ }^{42}$.

\section{Reflexiones relativas a la interpretación del límite de cita de la sentencia Nintendo}

28. La interpretación de este precepto realizada tanto por el AG como por el TJUE en nuestro parecer, no está exenta de crítica. En primer lugar, porque estamos ante una aplicación analógica de la regulación existente en el derecho marcario respecto al uso publicitario de la marca ajena y, no, como se pretende, en una interpretación teleológica del precepto del RDC. En segundo lugar, los contornos que se determinan por el AG y el TJUE respecto a este límite presentan ciertos matices difusos o poco claros.

29. Respecto a la primera de las cuestiones señaladas, hemos de plantearnos el tenor de la redacción del propio límite. Recordemos que el art.20.1 c) establece que "los actos de reproducción realizados con fines de cita o docentes, siempre que dichos actos sean compatibles con los usos comerciales, no menoscaben la explotación normal del dibujo o modelo y se mencione la fuente". Si comparamos este precepto con la regulación existente en otras ramas de la propiedad intelectual "latu sensu" (propiedad intelectual y propiedad industrial), encontramos similitudes importantes en el ámbito de la propiedad intelectual (derecho de autor).

En primer lugar, es remarcable que la estructura de la redacción del art.20.1 c) recuerda ampliamente a la de la "regla de los tres pasos", recogida en el art. 9.2 del Convenio de Berna: "Se reserva a las legislaciones de los países de la Unión la facultad de permitir la reproducción de dichas obras en determinados casos especiales, con tal que esa reproducción no atente a la explotación normal de la obra ni cause un perjuicio injustificado a los intereses legítimos del autor". ${ }^{43}$

Por otro lado, encontramos también en este Convenio, en su artículo 10 la regulación básica del límite de cita $^{44}$. Este límite aparece recogido de una manera más detallada nuestra ley de propiedad intelectual: "Es lícita la inclusión en una obra propia de fragmentos de otras ajenas de naturaleza escrita, sonora o audiovisual, así como la de obras aisladas de carácter plástico o fotográfico figurativo, siempre que se trate de obras ya divulgadas y su inclusión se realice a título de cita o para su análisis, comentario o juicio crítico. Tal utilización solo podrá realizarse con fines docentes o de investigación, en la medida justificada por el fin de esa incorporación e indicando la fuente y el nombre del autor de la obra utilizada." 45

Vemos que en este caso la limitación de la cita es clara, la misma puede realizarse pero dentro de unos márgenes claramente determinados (fines docentes o de investigación, de manera justificada y citando de manera correcta y completa la fuente).

\footnotetext{
41 Ídem.

${ }^{42}$ Este aspecto es mencionado de manera expresa por el AG: "corresponde al juez nacional determinar si la inclusión de la mención «para Wii» en los embalajes y los anuncios a través de un sitio de Internet en relación con los productos de BigBen Francia satisface este requisito" (\$ 81).

${ }^{43} \mathrm{Si}$ bien es cierto que en el texto del art.20.1 c) el enunciado literal es que "dichos actos sean compatibles con los usos comerciales" la interpretación dada por el TJUE (aunque extraída de la regulación marcaria) corresponde con el enunciado de la tercera condición contemplada por el art.9.2 de la Convención de Berna, que no se cause un perjuicio injustificado a los intereses legítimos del titular. STJUE Nintendo, $\$ 79$.

${ }^{44}$ Art. 10 Convenio de Berna; "1) Son lícitas las citas tomadas de una obra que se haya hecho lícitamente accesible al público, a condición de que se hagan conforme a los usos honrados y en la medida justificada por el fin que se persiga, comprendiéndose las citas de artículos periodísticos y colecciones periódicas bajo la forma de revistas de prensa. (...) 3) Las citas y utilizaciones a que se refieren los párrafos precedentes deberán mencionar la fuente y el nombre del autor, si este nombre figura en la fuente".

${ }^{45}$ Párrafo primero del artículo 32.1 del Real Decreto Legislativo 1/1996, de 12 de abril, por el que se aprueba el texto refundido de la Ley de Propiedad Intelectual, regularizando, aclarando y armonizando las disposiciones legales vigentes sobre la materia (de aquí en adelante, “TRLPI").
} 
30. Esta regulación del límite de cita por la propiedad intelectual es muy similar a la intencionalidad con la que el art.20.1 c) fue concebido en el Libro Verde sobre el diseño comunitario. Se pretendía que estuvieran permitida la reproducción de los diseños para fines de enseñanza. Ciertamente, en este texto del Libro Verde la excepción aparece con unos límites demasiado estrechos ${ }^{46}$, con lo cual podría resultar comprensible su ampliación a la cita siempre, entendemos dentro de un contexto educativo o científico $^{47}$ (esto es de una manera similar a la concepción de este límite en el derecho de autor) ${ }^{48}$.

31. Por otro lado, dentro de la propiedad industrial el precepto que más podría asemejarse (y con el que tanto el AG como el TJUE lo han identificado) lo encontramos en la letra c) del apartado 1 del art. 14 de Reglamento de Marca de la Unión Europea (de aquí en adelante "RMUE"): "Una marca de la Unión no permitirá a su titular prohibir a un tercero hacer uso, en el tráfico económico: de la marca de la Unión, a efectos de designar productos o servicios como correspondientes al titular de esa marca o de hacer referencia a los mismos, en particular cuando el uso de esa marca sea necesario para indicar el destino de un producto o de un servicio, en particular como accesorios o piezas de recambio". ${ }^{49,50}$ Este uso realizado por el tercero deberá ser conforme a las prácticas leales en materia industrial o comercial (art.14.3 RMUE).

Este precepto está especialmente dirigido a la posibilidad de uso de una marca ajena en determinados sectores de actividad o mercados para los que dicha referencia tiene un interés justificado, como son, por ejemplo, los mercados de accesorios, recambios, mantenimiento o reparación. En este caso, por un lado, no se dificulta la competencia en mercados conexos al del titular de la marca y, por ende, se facilita una información adecuada para facilitar la elección del consumidor.

32. No obstante, la existencia de este límite no justifica cualquier tipo de uso. De hecho, el propio TJUE hace referencia a la sentencia del caso "Gillette" en la que se hace una interpretación bastante restrictiva de este límite. Así en esta sentencia se entiende que "el uso de la marca ajena por un tercero es necesario para indicar el destino de un producto comercializado por éste cuando dicho uso constituye en la práctica el único modo de proporcionar al público una información comprensible y completa sobre este destino con objeto de mantener el sistema de competencia no falseado en el mercado de este producto".

Además de lo anterior, y como decíamos en un momento precedente, este uso ha de adecuarse a los parámetros de lealtad competitiva. Esto supone, como afirma Galán Corona "que el uso por el tercero de la marca ajena no pueda dar la impresión en el público interesado de que existe un vínculo comercial entre él o sus productos o servicios y el titular de la marca o persona autorizada para utilizarla, o que dicho uso del tercero no suponga un aprovechamiento indebido por éste del carácter distintivo o del renombre de la marca, ni el descrédito o denigración de la marca o la presentación de los productos del tercero como una imitación o réplica de los que la llevan".

33. Se pueden extrapolar, por tanto, tres requisitos fundamentales que serían aplicables para considerar como permitido el uso tanto de marcas como de diseños comunitarios ajenos:

- el primero sería la necesidad de hacer referencia al derecho de propiedad industrial ajeno por razones justificadas;

- el segundo, comprendería la imposibilidad de proporcionar una información completa al público por otro medio, $\mathrm{y}$

46 "Finally it should remain posible to accomplish acts relating to the design for the purpose of teaching design such reproducing the design in a school for designer, which act in the absence of a provision to the contrary wpuld constitute an infringement". http://aei.pitt.edu/1785/1/design_gp_1.pdf

${ }^{47}$ Por ejemplo, la reproducción del diseño para su cita en un libro de texto o en un artículo de investigación.

${ }^{48}$ Sobre esta cuestión se han pronunciado en el mismo sentido, como indica Rosalía EstupiÑan, los profesores Musker y Stone. Vid. R. EstupIÑAN CÁCERES, "El alcance de la reproducción de diseños comunitarios ajenos hecha con fines de cita. Reflexiones a propósito del caso Nintendo vs BigBen Interactive", La Ley mercantil, № 43, Wolters Kluwer, 2018, pp.7-8.

${ }^{49}$ Reglamento (UE) 2017/1001 del Parlamento Europeo y del Consejo, de 14 de junio de 2017, sobre la marca de la Unión Europea (Texto pertinente a efectos del EEE). OJ L 154, 16.6.2017, p. 1-99

${ }^{50}$ Un precepto similar lo encontramos en el art. 37 c) de la Ley 17/2001, de 7 de diciembre, de Marcas. 
- el tercero, consistiría en la existencia de una clara distinción entre el origen de los productos propios y los del tercero a los que se hace referencia mediante el uso de un derecho de propiedad industrial de su propiedad.

34. En el caso en cuestión es cuestionable que se cumplieran los requisitos mencionados, especialmente los dos primeros.

En primer lugar, en el caso en cuestión no se está reproducción una imagen de la consola para la que son compatibles dichos objetos, sino que serán reproducidos los diseños de elementos que son sustituibles por los ofertados por un competidor.

En segundo lugar, existen otros medios, distintos a la reproducción del diseño, para poder proporcionar al público una información completa y comprensible de los productos ofertados, por ejemplo, con la mención la marca de la consola ("Nintendo Wii") e indicando su compatibilidad con la misma y explicando brevemente las características del complemento anunciado ${ }^{51}$.

35. Por otro lado, el propio artículo 20.1 c) RDC establece como obligación para poder considerar como legítimo este uso, la necesidad de la citar de la fuente. Este requisito nos vuelve a recordar la configuración del límite de cita e ilustración establecido en las leyes de propiedad intelectual (derecho de autor). Sería necesaria, pues una correcta cita del diseño en cuestión. En nuestra opinión, la referencia a la marca, como sugieren tanto el AG como el TJUE, no nos parece suficiente. En nuestra opinión, no bastaría con hacer referencia al titular del diseño, sino que sería necesario mencionar al autor del mismo, amén de otros elementos adicionales que permitan determinar de una manera completa este origen.

36. Por último, y como reflexión complementaria a esta crítica, nos parece que tanto el AG como el TJUE han abordado este problema desde una perspectiva restringida, limitada a la situación, en su opinión, más próxima a esta situación, pero sin tener en cuenta otra de las caras del espectro de protección que puede afectar a un producto: la propiedad intelectual (derecho de autor). Recordemos que un producto protegido por diseño industrial, si es original, puede ser además protegido por derecho de autor ${ }^{52}$. Cómo mencionamos anteriormente, la excepción de cita en el caso del derecho de autor tiene unos contornos muy diferentes a los que se le ha dado a esta excepción por el TJUE en el caso del diseño industrial. ¿Qué pasará, entonces, en aquellos casos en los que un diseño esté protegido por ambas figuras y se utilice en la publicidad por un competidor? Pues que, en este caso, si bien no supondrá una infracción de diseño comunitario (en el caso de que cumpla todos los requisitos mencionados), si lo será de derecho de autor.

\section{Consideraciones finales}

37. En nuestra opinión, en esta Sentencia el TJUE intenta simplificar situaciones complejas mediante soluciones simplificadoras, con una referencia continua a soluciones ya adoptadas en el derecho marcario de la UE, lo cual, aunque útil en determinadas ocasiones, puede resultar claramente desaconsejable en otras.

\footnotetext{
${ }^{51}$ En el mismo sentido, S. Louredo CASAdo, "Los límites al derecho de diseño relacionados con indicaciones de compatibilidad", Revista de derecho de la competencia y la distribución, №. 24, 2019.

${ }_{52}$ Esta doble protección ha sido objeto de una larga tradicción jurisprudencial a nivel de la UE, como se recuerda en el Legal review on industrial design protection in Europe: "La regulación en relación con la "superposición" entre la ley de diseño y los derechos de autor ha sido aclarada por el Tribunal de Justicia en Flos v. Semeraro. Incluso los Estados miembros con barreras hasta ahora infranqueables para la acumulación de los derechos de autor y la protección del diseño han alterado sus enfoques. Se recomienda que cualquier Estado miembro que aún no haya modificado sus leyes, lo haga pronto. Cualquier disparidad que exista a nivel de los Estados miembros con respecto a este tema puede deberse simplemente a inercia legislativa o mala interpretación judicial en esos Estados miembros".Traducción propia. (D. PARRILLI Y OTROS, Legal review on industrial design protection in Europe Under the contract with the Directorate General Internal Market, Industry, Entrepreneurship and SMEs (MARKT2014/083/D), Comisión Europea, 2017, p.161). Sobre la complementariedad de protecciones, per alia, vid. F. CARBAJO CASCÓN, "Bienes inmateriales híbridos y concurrencia de protecciones: formas de tutela de las obras aplicadas a la industria", Pe. i.: Revista de propiedad intelectual, № 55, 2017, págs. 13-58.
} 
Así, tenemos por una parte, que se clarifica una situación procesal frecuente de una manera práctica y coherente, estableciéndose que en el supuesto de un litisconsorcio pasivo en un caso de infracción de diseño industrial, el tribunal del domicilio de uno de los demandados (siempre que se encuentre sito en un Estado miembro) podrá tener competencia para dictar las sanciones y medidas con un alcance sobre todo el territorio de la UE sobre otro/s infractor/es domiciliado en otros Estados miembros.

Por otra parte, respecto a la ley aplicable a estos casos de infracción de diseño industrial transnacional e intercomunitaria, el TJUE se hace directamente eco de la solución general adoptada por el derecho marcario, en el caso Coty (la ley del país en el que se encuentra el lugar en el que se ha producido el hecho generador del daño), aunque ofreciendo dos matizaciones que pueden dar lugar a una pluralidad de interpretaciones. Recordemos que respecto al ofrecimiento a la venta en un sitio internet, el TJUE determina que se podría considerar como ley aplicable la del lugar en el que se ha en que se ha iniciado el proceso de publicación de la oferta a la venta por parte de dicho operador en el sitio de su propiedad. Por otro lado, en el transporte a un Estado miembro distinto de aquel en el que está establecido el operador de productos que supuestamente infringen derechos protegidos, se plantea que se ha de apreciar de manera global el comportamiento de dicho demandado, a efectos de determinar el lugar en el que éste cometió o pudo cometer el acto de infracción inicial, que está en el origen del comportamiento reprochado. Si analizamos atentamente estas dos afirmaciones, veremos que ciertos aspectos no han sido suficientemente matizados. Por ejemplo, cuando se habla "del lugar en el que se ha en que se ha iniciado el proceso de publicación de la oferta a la venta", ¿qué pasaría en los casos en los que el administrador de la página web se encuentra en un Estado miembro (o no) diferente del aquel del domicilio del infractor? o ¿qué pasaría en el caso de que el sitio "no sea de su propiedad" porque se trate, por ejemplo, de una plataforma propiedad de un tercero? Y, en el segundo supuesto planteado, en un caso como el de Nintendo, ¿cuál sería el origen del comportamiento reprochado? ¿La fabricación o el permiso o el mandato dado a la filial para la venta por medio de Internet de los productos? A nuestro entender, al entrar el TJUE a analizar dos conductas concretas, estas cuestiones habría debido ser tenidas en cuenta, para aportar soluciones que, sin llegar al determinismo del AG en sus conclusiones, estuvieran menos sujetas a la especulación.

Por último, respecto a la interpretación del límite de cita en el diseño comunitario, nos parece que el TJUE ha simplificado en demasía su razonamiento, obviando una cuestión clave en la protección de los diseños, como es la de la potencial protección complementaria por propiedad intelectual (derecho de autor). Teniendo en cuenta que ya existía una solución en el derecho marcario que puede aplicarse en las situaciones enunciadas y que se puede complementar con explicaciones adicionales para que el consumidor pueda tener toda la información necesaria, nos parece, por consiguiente, que la solución aportada es contraria al principio de interpretación estricta de los límites de la propiedad intelectual e incongruente con la posibilidad de la aplicación cumulativa sobre los diseños de la protección por diseño comunitario y por derecho de autor. A nuestro entender, el TJUE habría podido salvar esta cuestión haciendo una interpretación más estricta de esta excepción y más coherente con el sentido primigenio de la misma. 